\title{
ASCARIS LUMBRICOIDES INFECTION INDUCES BOTH, REDUCTION AND INCREASE OF ASTHMA SYMPTOMS IN A RURAL COMMUNITY
}

Josefina Zakzuk; Stephanie Casadiego; Ana Mercado; Nelson, Alvis-Guzman; Luis Caraballo.

\begin{abstract}
Several studies, in different populations and environments, have shown that severe and light helminthiases diminish and increase allergy symptoms, respectively. However, data on the simultaneous presence of these contrary effects in a single community is lacking. In a rural community from Colombia, effects of helminthiases on allergy were evaluated. In the study population, age and gender-adjusted prevalence of asthma and rhinitis symptoms in the last year was $14.6 \%$ and $34.1 \%$, respectively $(\mathrm{N}=739)$. By stool exam, ascariasis and trichuriasis were $62.5 \%$ and $35.7 \%$, respectively. Significant odds ratio (OR) for asthma presentation were Ascaris sensitization, by specific-lgE (aOR: $2.69,95 \% \mathrm{Cl}$ : $1.21-5.98$ ) or skin prick test (OR: $3.59,95 \% \mathrm{Cl}: 1.55-8.29)$. Moderate/severe ascariasis was protective from asthma (aOR: $0.34,95 \% \mathrm{Cl}: 0.12-0.99$ ) and moderate/severe trichuriasis from rhinitis (aOR: $0.35,95 \% \mathrm{Cl}: 0.15-0.80$ ). In conclusion, in a rural tropical village, ascariasis exerts risk and protective effects on asthma symptoms, an influence associated with the severity of the infection.
\end{abstract}

\section{Keywords}

Epidemiology, IgE, Parasites, Asthma, Ascaris 